\title{
Determination of the Mineral Composition \\ of the Lake Bottom Sediments \\ by X-Ray Diffraction Method \\ and Physico-Chemical Modelling
}

\author{
Roman V. Smelyy ${ }^{\mathrm{a}}$, \\ Ekaterina V. Kaneva ${ }^{a}$, Anastasiya V. Oshchepkova ${ }^{a}$, \\ Valerii A. Bychinskii ${ }^{a}$, Tat'yana S. Aisueva ${ }^{a}$, \\ Aleksandr A. Shchetnikov ${ }^{c}$, Galina V. Pashkova ${ }^{c}$, \\ Igor' S. Yakimov ${ }^{\mathrm{b}}$ and Aleksandr L. Finkelshtein ${ }^{\mathrm{a}}$ \\ ${ }^{a}$ Vinogradov Institute of Geochemistry, SB RAS \\ IA Favorsky Str., Irkutsk, 664033, Russia \\ ${ }^{b}$ Siberian Federal University \\ 79 Svobodny, Krasnoyarsk, 660041, Russia \\ 'Institute of the Earth's Crust, SB RAS \\ 128 Lermontov Str., Irkutsk, 664033, Russia
}

Received 09.04.2019, received in revised form 10.04.2019, accepted 19.08.2019

The paper reports comparison of three approaches to define the contents of minerals and mineral groups in the carbonate-silicate lake bottom sediments. The two approaches are based on the method of X-ray powder diffraction. The first one treats with the Rietveld Method in the software DIFFRAC Plus diffractometer D8 Advance (PDF-2 database). The second one uses the method of reference intensities (corundum ratios) and optimization of the model powder patterns from the X-ray phase standards of PDF-2 database and equations of the element balance with regularization of the least square functional. The third approach of physic-chemical modeling selects probable single mineral and multi-component phases through modelling the sold solutions, and it uses the data on the element composition obtained by XRF technique, as well as the data of X-ray diffraction on the qualitative mineral composition. Thirty samples of bottom sediment cores taken in the Zun-Torey Lake in East Siberia were analyzed by the three approaches described herein. The contents of mineral groups (feldspars, quartz, clay minerals and carbonates) varied within the range 10-40 mass \%. The discrepancies between obtained results show the standard deviation ranging from 2 to 9 mass \%. A relative standard deviation commonly provides the value below $30 \%$, so such determinations could be considered quantitative ones. With regard to the acquired data, it is hard to prefer this or that approach.

(C) Siberian Federal University. All rights reserved

* Corresponding author E-mail address: srv47@yandex.ru 
Available data was employed to assess the error of X-ray phase powder analysis in measuring the abundance of mineral groups in the carbonate-silicate sedimentary rocks in the absence of reference materials to compare with certified mineral composition.

Keywords: quantitative X-ray phase analysis, physico-chemical modeling, carbonate-silicate lake bottom sediments.

Citation: Smelyy R.V., Kaneva E.V., Oshchepkova A.V., Bychinskii V.A., Aisueva T.S., Shchetnikov A.A., Pashkova G.V, Yakimov I.S., Finkelshtein A.L. Determination of the mineral composition of the lake bottom sediments by x-ray diffraction method and physico-chemical modelling, J. Sib. Fed. Univ. Chem., 2019, 12(3), 382-394. DOI: 10.17516/1998-2836-0135.

\title{
Определение минерального состава
}

озерных донных отложений методами

рентгеновской дифракции

\section{и физико-химического моделирования}

\author{
Р.В. Смелый ${ }^{a}$ Е.В. Канева ${ }^{a}$, А.В. Ощепкова ${ }^{a}$, \\ В.А. Бычинский ${ }^{a}$, Т.С. Айсуева ${ }^{a}$, А.А. Щетниковв \\ Г.В. Пашкова ${ }^{\text {, И.С. Якимов }}{ }^{\sigma}$, А.Л. Финкельштейн ${ }^{\mathrm{a}}$ \\ ${ }^{a}$ Институт геохимии им. А.П. Виноградова СО РАН \\ Россия, 664033, Иркутск, ул. Фаворского, 1А, а/я 9 \\ ${ }^{6}$ Сибирский федеральньий университет \\ Россия, 660041, Красноярск, пр. Свободный, 79 \\ ${ }^{8}$ Институт земной коры СО РАН \\ Россия, 664033, Иркутск, ул. Лермонтова, 128
}

Сопоставлены три способа определения содержания минералов и минеральных групп в карбонатно-силикатных озерных донных отложениях. Два способа основаны на методе рентгеновской порошковой дифрактометрии. Первый использует обработку дифрактограмм методом Ритвельда в программном обеспечении DIFFRAC Plus дифрактометра D8 Advance (база данных PDF-2). Второй применяет метод ссылочных интенсивностей (корундовых отношений) и оптимизацию модельной дифрактограммы из рентгенофазовых эталонов базы PDF-2 и уравнений элементного баланса с использованием регуляризированного метода наименьиих квадратов. Третий способ, основанньй на физико-химическом моделировании, выполняет подбор вероятных мономинеральных и многокомпонентных фаз с помощью модели твердых растворов и использует данные об элементном составе, полученные с помощью рентгенофлуоресцентного метода анализа и данные рентгеновской дифрактометрии о качественном минеральном составе. 30 образцов керна донных отложений оз. Зун-Торей (Восточная Сибирь) были проанализированы тремя

$$
-383-
$$


упомянутымиспособами. Содержанияминеральныхгрупп (полевыешпаты, квари, глинистые минераль, карбонаты) варьировали в диапазоне приблизительно 10-40 мас. \%. Расхождения между результатами определений тремя способами характеризуются стандартным отклонением в диапазоне 2-9 мас. \%. Относительное стандартное отклонение, как правило, составляло величину менее 30 \%, поэтому такие определения можно считать количественными. На основании полученных данных трудно отдать предпочтение какомулибо из рассмотренных способов. Приведенные данные позволили оценить погрешность рентгенофазового порошкового анализа при определении содержания минеральньх групп в карбонатно-силикатных осадочных породах в отсутствие стандартных образиов сравнения с аттестованным минеральным составом.

Ключевые слова: количественный рентгенофазовый анализ, физико-химическоемоделирование, карбонатно-силикатныле озерные донные отложения.

\section{Введение}

Осадки континентальных озер представляют собой природные архивы, несущие информацию об условиях осадконакопления, обусловленных изменениями природной среды и климата в прошлом. Специальный интерес представляет изучение осадков озер Восточной Сибири для палеоклиматических реконструкций внутриконтинентальных регионов. Палеоклиматические исследования осадков озерных отложений опираются на комплекс методов анализа вещества осадков - литологический, палинологический, геохимический, палеомагнитный, анализ изотопного состава кислорода и углерода и некоторые другие [1-5]. Для определения элементного состава осадков широко используется рентгенофлуоресцентный метод анализа, например [2-4, 6-9]. Минеральный состав осадков определяют, как правило, методом рентгеновской дифракции $[1-5,10,11]$. Индикаторами изменения режима осадконакопления, обусловленного изменением климата водосборного бассейна, могут служить такие минеральные группы, как карбонатные минералы, кварц, полевые шпаты, глинистые минералы и некоторые другие [1, 2, 5, 10-13]. Содержания основных породообразующих элементов определяются рентгенофлуоресцентным методом с хорошей точностью на уровне 1-5 отн. \% и менее [6]. Количественное определение минерального состава осадочных горных пород методом рентгеновской дифракции представляет собой существенно более сложную задачу по ряду причин, среди которых следует отметить неопределенность идентификации отдельных минералов, составляющих минеральные группы (глинистые минералы, карбонатные минералы, полевые шпаты и др.), и отсутствие стандартных образцов осадочных горных пород с аттестованным минеральным составом. Погрешность определения минерального состава остается, как правило, неизвестной, несмотря на то, что погрешность метода рентгеновской дифракции, установленная в межлабораторном эксперименте, для искусственных смесей хорошо охарактеризованных минералов может быть менее $3 \%[14,15]$ и сопоставима с погрешностью рентгенофлуоресцентного метода.

Целью настоящей работы являлось сравнение трех различных способов определения минерального состава озерных карбонатно-силикатных отложений и оценка на этой основе вели- 
чины неопределенности минерального состава. Были сопоставлены следующие способы: (1) рентгенофазовый дифракционный анализ методом Ритвельда [16], (2) рентгенофазовый дифракционный анализ с обработкой мультирефлексным методом ссылочных интенсивностей, реализованный в [17], (3) физико-химическое моделирование (ФХМ) на основе данных об элементном составе $[18,19]$.

\section{Экспериментальная часть}

\section{Объект исследования}

Объектом настоящего исследования являются донные отложения оз. Зун-Торей, расположенного на юге Восточного Забайкалья и входящего в систему Торейских озер Зун-Торей -

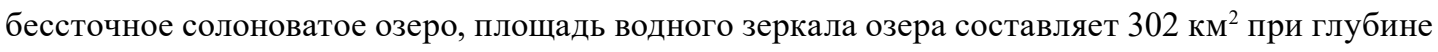
около 7 м. Керн донных отложений озера изучали в связи с палеоклиматическими исследованиями постоптимального периода голоцена (последние 5 - 6 тысяч лет). Керн был отобран гравитационным керноотборным устройством ударно-канатного типа. Керн диаметром 6-8 см и длиной 94 см был поделен на части с шагом 1 см. Масса каждого сантиметра керна была распределена среди различных методов анализа. Приблизительно 500 мг каждого образца было использовано для рентгенофлуоресцентного анализа, 2 г каждого третьего сантиметра керна для рентгенофазового анализа и определения связанных в минералах компонентов $-\mathrm{H}_{2} \mathrm{O}^{+}$и $\mathrm{CO}_{2}$. Предварительные оценки минерального состава донных отложений оз. Зун-Торей приведены в работе [20].

\section{Аппаратура и условия измерения}

Определение основных породообразующих элементов было выполнено на рентгеновском флуоресцентном спектрометре с волновой дисперсией S8 Tiger (Bruker AXS). Спектрометр оснащен рентгеновской трубкой мощностью 4 кBт с Rh-анодом и Ве-окном толщиной 75 мкм; коллиматорной маской, позволяющей анализировать образцы диаметром 8 мм. Для проведения измерений 200-300 мг порошка прессовали в таблетки на подложке из борной кислоты на гидравлическом прессе (усилие прессования 10 т) [8]. Экспозиции измерения аналитических линий выбраны таким образом, чтобы обеспечить стандартное отклонение измерения скорости счета на уровне менее 1 отн. \%. Общее время измерения одной пробы составляло 10 мин. Детали методики измерения описаны в работе [6].

Определение минерального (фазового) состава проводили на рентгеновском порошковом дифрактометре D8 ADVANCE (Bruker). Дифрактометр оснащен сцинтилляционным детектором и зеркалом Гебеля. Источником $\mathrm{CuK \alpha}$ излучения служит рентгеновская трубка с $\mathrm{Cu}$ анодом. Напряжение и ток рентгеновской трубки: 40 кВ, 40 мА. Измерения проводили в пошаговом режиме: шаг сканирования $0.02^{\circ} 2 \theta$ в диапазоне дифракционных углов $2 \theta$ от 3 до $80^{\circ}$, время экспозиции $1 \mathrm{c}$, вращение образца - 15 об/мин. Общее время измерения одной дифрактограммы составляло около 60 мин. Образцы для измерения готовили набивкой и выравниваем порошка в специальной кювете. Относительное стандартное отклонение измерения интегральной интенсивности главных пиков кварца и доломита, оцененное по результатам измерения пяти приготовленных образцов чистого кварца и доломита, составило 2.7 \% для кварца и $3 \%$ для доломита.

$$
-385-
$$




\section{Рентгенофазовый дифракиионный анализ}

Обработка дифрактограмм выполнена с использованием двух пакетов программных средств - пакет DIFFRAC plus дифрактометра D8 ADVANCE [21, 22] и пакет ИПС ФИ [17], разработанный в лаборатории рентгеновских методов анализа Сибирского федерального университета.

Программное обеспечение DIFFRAC plus включает идентификацию минеральных фаз с помощью базы данных порошковой дифрактометрии PDF-2 (2007 г.) [23] с применением программного обеспечения EVA [21]. Количественный фазовый анализ реализован в программе TOPAS 4 [22] и основан на полнопрофильном анализе по методу Ритвельда [16].

Программное обеспечение ИПС ФИ для идентификации минеральных фаз использует версию базы данных PDF-2 [23]. ИПС ФИ интегрирует кластерную рентгенофазовую идентификацию с количественным фазовым анализом по мультирефлексному варианту метода ссылочных интенсивностей (Reference Intensity Ratio, RIR) [24]. Подход основан на оптимизации модельной дифрактограммы из рентгенофазовых эталонов базы PDF-2 и уравнений элементного баланса с использованием регуляризированного метода наименьших квадратов [25]. В качестве отношения интенсивностей пиков определяемых фаз к интенсивности пика фазы сравнения используются корундовые отношения (отношения интенсивности пика фазы и главного пика корунда), представленные в базе PDF-2.

\section{Физико-химическое моделирование минерального состава}

на основе данных о содержании элементов

Метод физико-химического моделирования (ФХМ) - один из способов оценки соотношения минералов в образцах осадочных горных пород, исходя из содержаний элементов использовался ранее для исследования донных осадков оз. Байкал $[18,19]$. Расчеты выполнены с помощью программного комплекса «Селектор» [26], который представляет собой набор программных процедур, реализующих алгоритм минимизации свободной энергии методом выпуклого программирования. Предварительно с помощью метода рентгеновской дифракции определены основные компоненты: кварц, анкерит, кальцит, доломит, полевые шпаты, мусковит и глинистые минералы. Расчет минерального состава начинается с подготовки данных о химическом составе пробы донных отложений. Затем выполняется подбор вероятных как мономинеральных, так и многокомпонентных фаз. С помощью модели твердых растворов (списка миналов) определяются сводные стехиометрические формулы полевых шпатов и слоистых алюмосиликатов. Разработанная методика расчета и списки миналов твердых растворов описаны на примере моделирования минерального состава байкальских осадков в работах $[5,18,19]$.

\section{Результаты и обсуждение}

На рис. 1 представлена дифрактограмма одного из исследуемых образцов донных отложений. В образцах идентифицированы минеральные фазы, список которых приведен в табл. 1.

Вариации содержания основных породообразующих элементов в пересчете на оксиды, определенные рентгенофлуоресцентным методом, а также содержания конституционной воды $\mathrm{H}_{2} \mathrm{O}^{+}, \mathrm{CO}_{2}$, определенные гравиметрическим и титриметрическим методами анализа, при- 


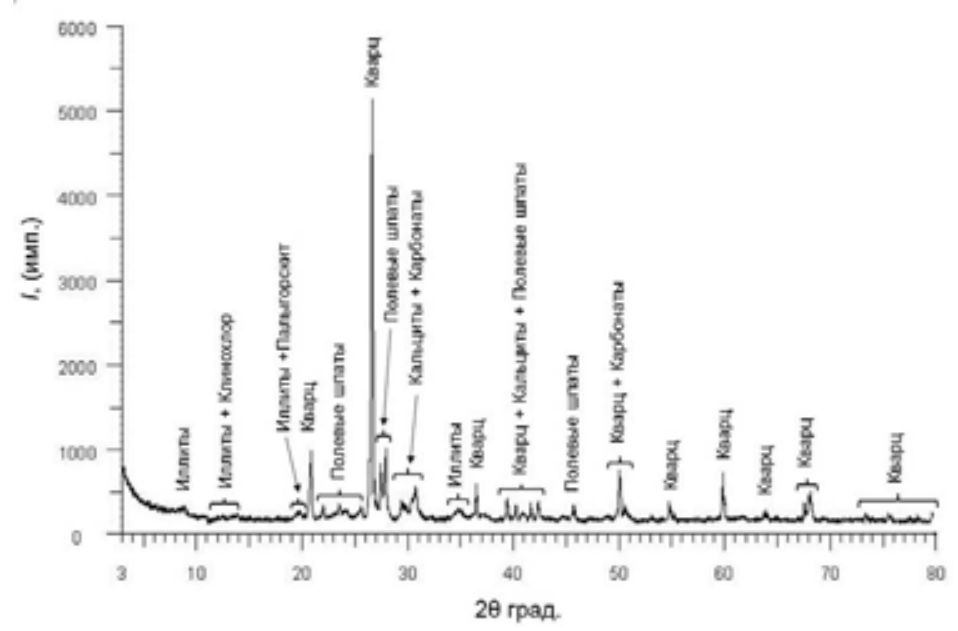

Рис. 1. Дифрактограмма одного из исследуемых образцов

Fig. 1. Diffractogram of one of the studied samples

Таблица 1. Минеральные фазы, идентифицированные в образцах осадков

Table 1. Mineral phases identified in sediment samples

\begin{tabular}{|c|c|c|}
\hline Имя минерала в базе PDF-2 & Код в базе PDF-2 & Химическая формула \\
\hline Кварц (Quartzlow) & $86-1560$ & $\mathrm{SiO}_{2}$ \\
\hline Доломит (Dolomite, ferroan) & 34- 517 & $\mathrm{Ca}(\mathrm{Mg}, \mathrm{Fe})\left(\mathrm{CO}_{3}\right)_{2}$ \\
\hline Анкерит (Ankerite)0 & $84-2066$ & $\mathrm{Ca}_{1.01} \mathrm{Mg}_{0.45} \mathrm{Fe}_{0.54}\left(\mathrm{CO}_{3}\right)_{2}$ \\
\hline Анкерит (Ankerite) & $84-2067$ & $\mathrm{Ca} \mathrm{Mg} \mathrm{Mg}_{0.27} \mathrm{Fe}_{0.73}\left(\mathrm{CO}_{3}\right)_{2}$ \\
\hline Кальцит (Calcite) & $72-1651$ & $\mathrm{CaCO}_{3}$ \\
\hline $\begin{array}{l}\text { Магнезиальный кальцит } \\
\text { (Calcitemagnesian) }\end{array}$ & $86-2336$ & $\left(\mathrm{Mg}_{0.129} \mathrm{Ca}_{0.871}\right)\left(\mathrm{CO}_{3}\right)$ \\
\hline Анортоклаз (Anorthoclase, disordered) & 9- 478 & $(\mathrm{Na}, \mathrm{K})\left(\mathrm{Si}_{3} \mathrm{Al}\right) \mathrm{O}_{8}$ \\
\hline Альбит (Albite, ordered) & $9-466$ & $\mathrm{NaAlSi}_{3} \mathrm{O}_{8}$ \\
\hline Иллит (Illite, trioctahe) & 9- 343 & $\mathrm{~K}_{0.5}(\mathrm{Al}, \mathrm{Fe}, \mathrm{Mg})_{3}(\mathrm{Si}, \mathrm{Al})_{4} \mathrm{O}_{10}(\mathrm{OH})_{2}$ \\
\hline Иллит 1 (Illite-1) & $29-1496$ & $\mathrm{~K}_{0.7} \mathrm{Al}_{2}(\mathrm{Si}, \mathrm{Al})_{4} \mathrm{O}_{10}(\mathrm{OH})_{2}$ \\
\hline Иллит 2 (Illite-2) & $43-685$ & $\mathrm{KAl}_{2}\left(\mathrm{Si}_{3} \mathrm{Al}\right) \mathrm{O}_{10}(\mathrm{OH})_{2}$ \\
\hline Клинохлор(Clinochlore) & $29-701$ & $(\mathrm{Mg}, \mathrm{Fe})_{6}(\mathrm{Si}, \mathrm{Al})_{4} \mathrm{O}_{10}(\mathrm{OH})_{8}$ \\
\hline Палыгорскит(Palygorskite O) & $88-1951$ & $\mathrm{Mg}_{5}\left(\mathrm{Si}_{4} \mathrm{O}_{10}\right)_{2}(\mathrm{OH})_{2}\left(\mathrm{H}_{2} \mathrm{O}\right)_{8}$ \\
\hline
\end{tabular}

ведены табл. 2. Низкое содержание общего органического углерода в образцах $\mathrm{C}_{\text {орг }}<0.3$ мас. \% свидетельствует о довольно низкой биопродуктивности водосборного бассейна. Вариации содержания оксидов алюминия и кремния обусловлены вариациями главным образом составляющих силикатных минералов и кварца, и вариации оксидов магния, кальция, железа и $\mathrm{CO}_{2}-$ вариациями составляющих карбонатных минералов.

На рис. 2 отражено распределение содержания $\mathrm{SiO}_{2}$ и содержания кварца и суммы полевых шпатов (альбит + анортоклаз) по глубине керна. Содержания кварца и полевых шпатов, пред- 
Таблица 2. Диапазоны содержания основных породообразующих компонентов

Table 2. The ranges of the main rock-forming components

\begin{tabular}{|c|c|c|c|c|c|}
\hline Компонент & $\begin{array}{c}\text { Диапазон } \\
\text { содержания, мас. \% }\end{array}$ & Компонент & $\begin{array}{c}\text { Диапазон } \\
\text { содержания, мас. \% }\end{array}$ & Компонент & $\begin{array}{c}\text { Диапазон } \\
\text { содержания, мас. \% }\end{array}$ \\
\hline $\mathrm{Na}_{2} \mathrm{O}$ & $1.7-3$ & $\mathrm{SiO}_{2}$ & $33-51$ & $\mathrm{Fe}_{2} \mathrm{O}_{3}$ & $3.5-6.5$ \\
\hline $\mathrm{MgO}$ & $4.5-11$ & $\mathrm{~K}_{2} \mathrm{O}$ & $2.8-3.5$ & $\mathrm{CO}_{2}$ & $6.1-15$ \\
\hline $\mathrm{Al}_{2} \mathrm{O}_{3}$ & $10-14$ & $\mathrm{CaO}$ & $7.4-13$ & $\mathrm{H}_{2} \mathrm{O}^{+}$ & $3.5-7.2$ \\
\hline
\end{tabular}

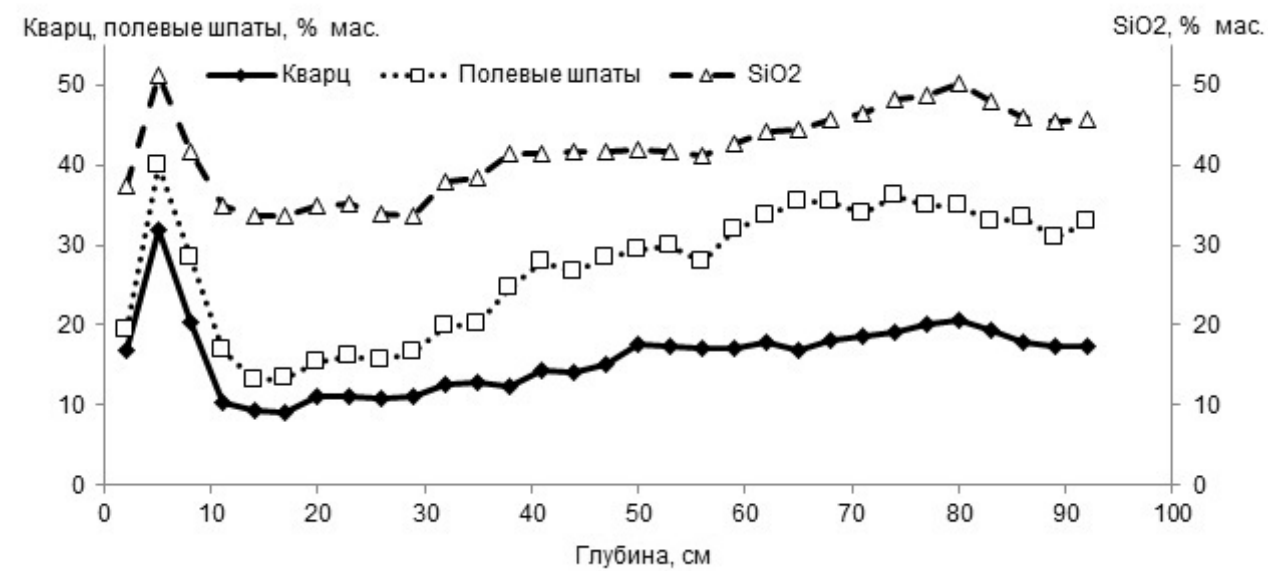

Рис. 2. Распределение содержания кварца, суммы полевых шпатов и оксида кремния по глубине керна

Fig. 2. The distribution of the quartz content, the sum of feldspars and silicon oxide over the core depth

ставленные на рис. 2, определены методом Ритвельда (пакет DIFRACplus, программа TOPAS 4, база PDF-2). Видно высокие корреляции между содержанием $\mathrm{SiO}_{2}$ и содержанием кварца и полевых шпатов (квадрат коэффициента корреляции $\mathrm{R}^{2}>0.85$ ). Полевые шпаты и кварц раскрывают терригенную составляющую осадков, и их содержание определяется режимом сноса вещества водосборного бассейна озера.

Например, в работе [10] отмечено, что содержание кварца и полевых шпатов в осадках тибетских озер обусловлено силой зимних муссонов. Пик в области горизонта 4-5 см свидетельствует о довольно резком увеличении сноса терригенного материала после периода с относительно низким поступлением этих минералов из водосборного бассейна.

На рис. 3 приведены зависимости содержания $\mathrm{CaO}$ и содержания суммы карбонатных минералов от глубины керна. Содержания карбонатных минералов определены с помощью программного пакета ИПС ФИ методом, основанным на корундовых отношениях. Установлена надежная корреляции между содержанием $\mathrm{CaO}$ и суммарным количеством карбонатных минералов ( $\left.\mathrm{R}^{2}>0.81\right)$. Однако сколько-нибудь значимой корреляции между содержаниями $\mathrm{CaO}$ и кальцитов $\left(\mathrm{CaCO}_{3}\left(\mathrm{Mg}_{0.129} \mathrm{Ca}_{0.871}\right) \mathrm{CO}_{3}\right)$ не установлено вследствие сравнительно низкого их содержания $(<3-4 \%$ ). В работе [1] отмечено, в частности, что содержание низкомагнезиального кальцита является маркером изменчивости физико-химических условий в водоеме. 


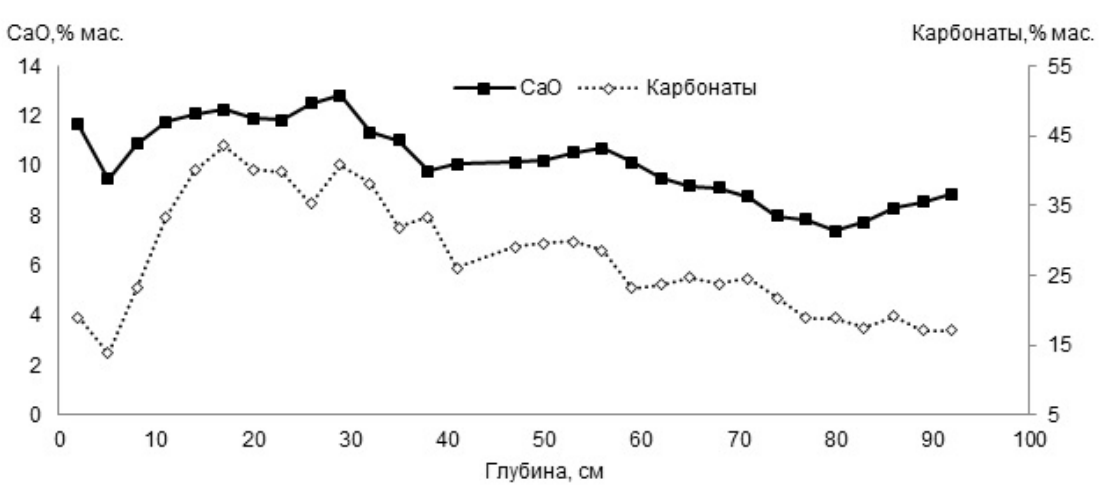

Рис. 3. Распределение суммарного содержания карбонатных минералов и оксида кальция по глубине керна донных отложений

Fig. 3. The distribution of the total content of carbonate minerals and calcium oxide over the core depth

На рис. 2 и 3 видно, что содержания минералов изменяются в 3-5 раз по глубине керна, а содержания компонентов $\mathrm{SiO}_{2}, \mathrm{CaO}$ - менее чем в 1.5 раза. Содержания минералов значительно более чувствительны к изменениям условий окружающей среды водосборного бассейна и, очевидно, являются предпочтительным маркером их изменений.

На рис. 4 даны результаты расчетов тремя упомянутыми способами зависимости содержания минеральных групп по глубине керна: с помощью программы TOPAS 4, программы ИПС ФИ и физико-химического моделирования (ФХМ) исходя из элементного состава (программный комплекс «Селектор» [26]). Несмотря на общее удовлетворительное согласие результатов расчетов, следует отметить, что расхождения в оценке содержания полевых шпатов больше, чем для кварца и карбонатов.

Это объясняется тем, что идентификация полевых шпатов осложняется присутствием изоморфных примесей в калиевом полевом шпате, вариацией Al-Si-упорядоченности в плагиоклазах, наложением пиков кварца при сравнительно высоком уровне его содержания. Наибольшее расхождение между определениями наблюдается для слоистых силикатов (илы, глины, слюды и др.). Расшифровка результатов рентгеновского дифракционного анализа слоистых силикатов, в частности глинистых минералов, требует применения специальных процедур обработки проб и специализированного математического аппарата, что, несомненно, сказывается на точности расчетов [13].

В табл. 3 приведены стандартные отклонения (SD) и относительные стандартные отклонения (RSD) между тремя рассматриваемыми способами определения минерального состава, рассчитанные по данным, изображенным на рис. 4. В табл. 3 отражены также средние содержания минеральных групп (C cp.).

На основании приведенных данных трудно отдать предпочтение какому-либо из рассмотренных методов оценки минерального состава. Стандартное отклонение между определениями содержания для кварца и карбонатов 2-5 \%, мас., для полевых шпатов и слоистых силикатов несколько больше 5-9 \%, мас. при сопоставимых вариациях содержания в диапазоне приблизительно 10-40 \%, мас. Относительное стандартное отклонение результатов определения для большинства пар методов меньше 30 \%, и такие определения следует считать количествен- 

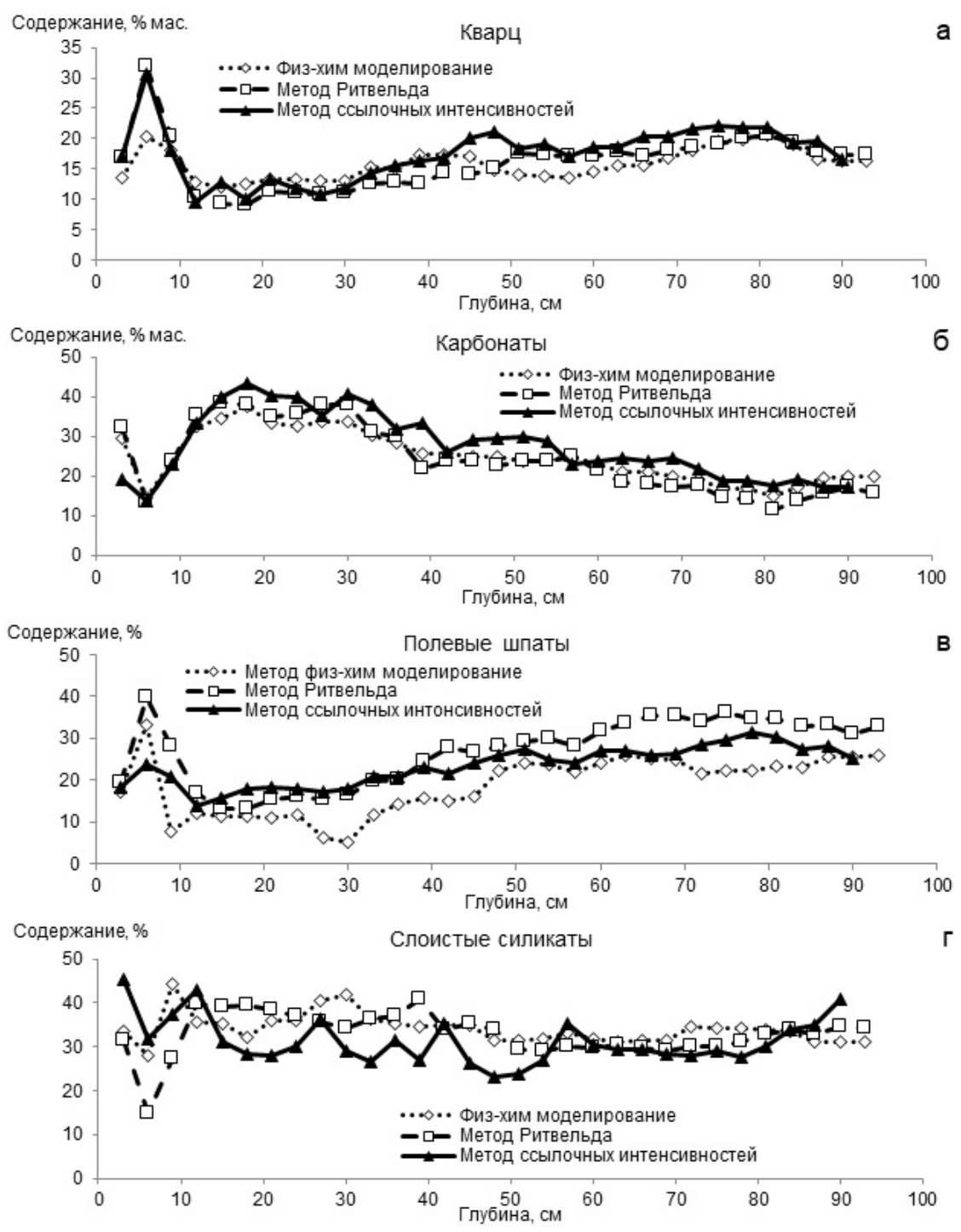

Рис. 4. Распределение содержания минеральных групп по глубине керна донных отложений: а - кварц; б - карбонатные минералы; в - полевые шпаты; г-слоистые силикаты

Fig. 4. The distribution of the content of mineral groups over the core depth of bottom sediments: $\mathrm{a}-\mathrm{quartz} ; \mathrm{b}-$ carbonate minerals; $\mathrm{c}$ - feldspars; $\mathrm{d}$ - layered silicates

Таблица 3. Стандартное отклонение между парами способов определения минерального состава

Table 3. Standard deviation between pairs of methods for determining the mineral composition

\begin{tabular}{|c|c|c|c|c|c|c|c|c|}
\hline \multirow{2}{*}{$\begin{array}{c}\text { Пары } \\
\text { методов оценки } \\
\text { минерального состава }\end{array}$} & \multicolumn{2}{|c|}{$\begin{array}{c}\text { Кварц } \\
\text { C cp. }-16 \% \text {, мас. }\end{array}$} & \multicolumn{2}{|c|}{$\begin{array}{c}\text { Карбонаты } \\
\text { С ср. }-25 \% \text {, мас. }\end{array}$} & \multicolumn{2}{|c|}{$\begin{array}{l}\text { Полевые шпаты } \\
\text { С ср. - } 23 \text { \%, мас. }\end{array}$} & \multicolumn{2}{|c|}{$\begin{array}{c}\text { Слоистые } \\
\text { силикаты } \\
\text { С cp. }-33 \% \text {, мас. }\end{array}$} \\
\hline & $\mathrm{SD} \%$, мас. & RSD & $\mathrm{SD} \%$, мас. & RSD & $\mathrm{SD} \%$, мас. & RSD & $\mathrm{SD} \%$, мас. & RSD \\
\hline TOPAS $4-\Phi X M$ & 3.1 & $19 \%$ & 2.6 & $11 \%$ & 9.0 & $33 \%$ & 5.2 & $16 \%$ \\
\hline ИПС ФИ - ФХМ & 2.8 & $18 \%$ & 4.4 & $18 \%$ & 6.3 & $33 \%$ & 6.0 & $18 \%$ \\
\hline TOPAS 4-ИПС ФИ & 2.2 & $12 \%$ & 5.0 & $20 \%$ & 5.7 & $21 \%$ & 6.0 & $18 \%$ \\
\hline
\end{tabular}


ными. Относительное стандартное отклонение более 30 \% наблюдается между результатами рентгенофазового и физико-химического анализов для случая определения полевых шпатов, что соответствует приближенно-количественному определению.

Следует отметить, что три рассмотренных способа определения минерального состава не являются полностью независимыми. В способах, основанных на измерении рентгеновской дифракции (TOPAS 4 , ИПС ФИ), используются одни и те же экспериментальные данные, но различные вычислительные алгоритмы и процедуры обработки дифрактограмм. В способе, основанном на физико-химическом моделировании, вместе с данными рентгенофлуоресцентного элементного анализа используются данные о качественном минеральном составе, полученные методом рентгеновской порошковой дифрактометрии. Кроме этого, вариации содержания некоторых элементов имеют явно выраженную корреляцию с вариациями содержания минеральных групп.

\section{Выводы}

Приведенные данные позволяют оценить погрешность рентгенофазового порошкового анализа при определении содержания минеральных групп в карбонатно-силикатных осадочных породах в отсутствие образцов сравнения с аттестованным минеральным составом и, следовательно, альтернативной возможности оценки этой погрешности. Оценка погрешности определения минерального состава имеет значение при проведении палеоклиматических реконструкций по результатам анализа озерных отложений. Такие минеральные виды, как кварц, и карбонатные минералы в карбонатно-силикатных озерных осадках могут быть определены с погрешностью 2-5 мас. \% при уровне содержания в диапазоне 10-40 мас. \%, содержание полевых шпатов и слоистых силикатов могут быть определены с погрешностью 6-9 мас. \% при сопоставимом уровне содержания. Следует также отметить, что метод физикохимического моделирования позволяет получить удовлетворительные оценки содержания минеральных групп на основе данных об элементном составе, полученном с помощью рентгенофлуоресцентного метода анализа, и он опирается на менее трудоемкие вычислительные процедуры.

\section{Благодарности}

Исследования выполнены с использованием оборудования Центра коллективного пользования «Изотопно-геохимических исследований» ИГХ СО РАН. Рентгенофлуоресцентный и рентгенофазовый анализы выполнены при финансовой поддержке Российского научного фонда (проект № 17-77-10118).

\section{Список литературы}

1. Скляров Е.В., Солотчина Э.П., Вологина Е.Г., Игнатова Н.В., Изох О.П., Кулагина Н.В., Склярова О.А., Солотчин П.А., Столповская В.Н., Ухова Н.Н., Федоровский В.С., Хлыстов О.М. Детальная летопись климата голоцена из карбонатного разреза соленого озера Цаган-Тырм, Западное Прибайкалье. Геология и геофизика 2010. T. 51(3), С. 303-328 [Skljarov E.V., Solotchina Je.P., Vologina E.G., Ignatova N.V., Izoh O.P., Kulagina N.V., Skljarova O.A., Solotchin P.A., Stolpovskaja V.N., Uhova N.N., Fedorovskij V.S., Hlystov O.M. Detailed Holocene climate record from the carbonate 
section of saline lake Tsagan-Tyrm (West Baik alarea). Russian Geology and Geophysics 2010. Vol. 51(3), P. 303-328 (In Russ.)]

2. Скляров Е.В., Солотчина Э.П., Вологина Е.Г., Изох О.П., Кулагина Н.В., Орлова Л.А., Склярова О.А., Солотчин П.А., Столповская В.Н., Ухова Н.Н. Климатическая история голоцена Западного Прибайкалья в карбонатной осадочной летописи озера Холбо-Нур. Доклады Академии наук 2010. T. 431(5), C. 668-674 [Skljarov E.V., SolotchinaJe.P., Vologina E.G., Izoh O.P., Kulagina N.V., Orlova L.A., Skljarova O.A., Solotchin P.A., Stolpovskaja V.N., Uhova N.N. The climatic history of the Holocene of the Western Baikal region in carbonate sedimentary chronicle of lake Holbo-Nur. Doklady Earth Sciences 2010. Vol. 431(5), P. 668-674 (In Russ.)]

3. Безрукова Е.В., Щетников А.А., Кузьмин М.И., Шарова О.Г., Кулагина Н.В., Летунова П.П., Иванов Е.В., Крайнов М.А., Кербер Е.В., Филинов И.А., Левина О.В. Первые данные об изменении природной среды и климата Жомболокского вулканического района (Восточный Саян) в среднем-позднем голоцене. Доклады Академии наук 2016. Т. 468(3), С. 323 327 [Bezrukova E.V., Shhetnikov A.A., Kuz'min M.I., Sharova O.G., Kulagina N.V., Letunova P.P., Ivanov E.V., Krajnov M.A., Kerber E.V., Filinov I.A., Levina O.V. First data on changes in the natural environment and climate of the Zhombolok volcanic region (East Sayan) in the middle-late Holocene. Doklady Earth Sciences 2016. Vol. 468(3), P. 323-327. DOI: 10.7868/S0869565216150172 (In Russ.)]

4. Минюк П.С., Борходоев В.Я., Горячев Н.А. Геохимические характеристики осадков оз. Эльгыгытгын (Чукотка) как показатели климатических изменений за последние 350 тыс. лет. Докладылкадемии наук 2011. Т. 436(2), C. 239-242 [Miniuk P.S., BorkhodoevV.Ia., Goriachev N.A. Geochemical characteristics of sediments from Lake El'gygytgyn, Chukotka Peninsula, as indicators of climatic variations for the past 350 ka. Doklady Earth Sciences 2011. Vol. 436(2), P. 239-242 (In Russ.)]

5. Кузьмин М.И., Бычинский В.А., Кербер Е.В., Ощепкова А.В., Горегляд А.В., Иванов Е.В. Химический состав осадков глубоководных Байкальских скважин как основа реконструкции изменений климата и окружающей среды. Геология и геофизика 2014. Т. 55(1), С. 3-22. [Kuz'min M.I., Bychinskij V.A., Kerber E.V., Oshhepkova A.V., Goregljad A.V., Ivanov E.V. The chemical composition of sediments of the Baikal deep-water wells as a basis for the reconstruction of climate change and the environment. Russian Geology and Geophysics 2014. Vol. 55(1), P. 3-22 (In Russ.)]

6. Амосова А.А., Чубаров В.М., Канева Е.В., Маркова Ю.Н. Определение основных породообразующих элементов, стронция и циркония рентгенофлуоресцентным методом для геохимической характеристики донных отложений. Аналитика и контроль 2017. Т. 21(1), С. 16-24 [Amosova A.A., Chubarov V.M., Kaneva E.V., Markova Yu.N. Determination of main rock-forming elements, strontium and zirconium by X-ray fluorescence analysis for the geochemical characterization of bottom. Analytics and Control 2017. Vol. 21(1), P. 16-24 (InRuss.)]

7. Пашкова Г.В., Мухамедова М.М., Айсуева Т.С., Финкельштейн А.Л., Щетников А.А. Использование способа стандарта-фона при определении элементов в донных отложениях методом рентгенофлуоресцентного анализа с полным внешним отражением. Аналитика и контроль 2018. T. 22(2), С. 136-146 [Pashkova G.V., Muhamedova M.M., Ajsueva T.S., Finkelshtein A.L., Shchetnikov A.A. Using Scattered Radiation Method in element analysis of sediments by total reflection X-ray fluorescence]. Analytics and Control 2018. Vol. 22(2), P. 136-146 (In Russ.)] 
8. Пашкова Г.В., Иванов Е.В., Айсуева Т.С., Щетников А.А., Маркова Ю.Н. Рентгенофлуоресцентное определение брома в донных отложениях озер для палеоклиматических исследований. Аналитика и контроль 2015. T. 19(4), С. 340-346 [Pashkova G.V., Ivanov E.V., Ajsueva T.S., Shchetnikov A.A., Markova Yu.N. Finkelshtein A.L. X-ray fluorescence determination of bromine in lake sediments for paleoclimatic studies. Analytics and Control 2015. Vol. 19(4), P. 340-346 (In Russ.)]

9. Rydberg J. Wavelength dispersive X-ray fluorescence spectroscopy as a fast, non-destructive and cost-effective analytical method for determining the geochemical composition of small loosepowder sediment samples. Journal of Paleolimnology 2014, Vol. 52, P. 265-276.

10. Opitz S., Wünnemann B., Aichner B., Dietze E., Hartmann K.,Herzschuh U., IJmker J., Lehmkuhl F., Li S., Mischke S., Plotzki A., Stauch G., Diekmann B. Late Glacial and Holocene development of Lake DonggiCona, north-eastern Tibetan Plateau, inferred from sedimentological analysis. Palaeogeography, Palaeoclimatology, Palaeoecology 2012. Vol. 337, P. 159-176.

11. Hupp B.N., Donovan J.J. Quantitative mineralogy for facies definition in the Marcellus Shale (Appalachian Basin, USA) using XRD-XRF integration. Sedimentary Geology 2018. Vol. 371, P. 16-31.

12. Жданова А.Н., Солотчина Э.П., Солотчин П.А., Кривоногов С.К., Даниленко И.В. Отражение изменений климата голоцена в минералогии донных осадков Ярковского плеса озера Чаны (юг Западной Сибири). Геология и геофизика 2017. Т. 58(6), C. 856-868 [Zhdanova A.N., Solotchina E.P., Solotchin P.A., Krivonogov S.K., Danilenko I.V. Reflection of Holocene climatic changes in mineralogy of bottom sediments from Yarkovsky Pool of Lake Chany (southern West Siberia). Russian Geology and Geophysics 2017. Vol. 58(6), P. $692-701$ (In Russ.)]

13. Солотчина Э.П. Структурный типоморфизм глинистых минералов осадочных разрезов и кор. Новосибирск: Гео, 2009. 234 с. [Solotchina Je.P. Structural typomorphism of clay minerals of sedimentary sections and crusts. Novosibirsk, Geo Publ., 2009. 234 p. (In Russ.)]

14. Madsen I.C., Scarlett N.V.Y., Cranswick L.M.D., Lwin T. Outcomes of the International Union of Crystallography Commission on Powder Diffraction Round Robin on Quantitative Phase Analysis. J. Appl. Cryst. 2001. Vol. 34, P. 409-426.

15. Ожогина Е.Г., Лебедева М.И., Горбатова Е.А. Межлабораторные сравнительные испытания в минералогических работах. Стандартныле образиьы 2017. Т. 13(2), С. $37-47$ [Ozhogina E.G., Lebedeva M.I., Gorbatova E.A. Interlaboratory comparison tests in mineralogical works. Reference materials 2017, Vol. 13(2), P. 37-47 (In Russ.)]

16. Young R.A. The Rietveld Method. Oxford: Oxford University Press, 1995. 298 p.

17. Якимов И.С., Дубинин П.С., Пиксина О.Е. Регуляризация метода ссылочных интенсивностей для количественного рентгенофазового анализа поликристаллов. Журнал Сибирского федерального университета 2009. T. 2(1), C. 71-80 [Jakimov I.S., Dubinin P.S., Piksina O.E. Regularization of the Reference Intensity Ratio Method for X-Ray Quantitative Phase Analysis of Powders. Journal of Siberian Federal University 2009. Vol. 2(1), P. 71-80 (In Russ.)]

18. Ощепкова А.В., Кузьмин М.И., Бычинский В.А. Реконструкция минерального состава глубоководных байкальских осадков на основе их химического состава. Известия Иркутского государственного университета. Науки о Земле 2013. T. 6(1), C. 122-132 [Oshhepkova A.V., Kuz'min M.I., Bychinskij V.A. Reconstruction of mineral composition of deep-sea Baikal sediments 
on the basis of their chemical composition. Proceedings of Irkutsk State University. Earth Sciences 2013. Vol. 6(1), P. 122-132 (In Russ.)]

19. Ощепкова А.В., Кузьмин М.И., Бычинский В.А., Солотчина Э.П., Чудненко К.В. Модели твердых растворов для расчета минерального состава донных осадков озера Байкал: новый подход к палеоклиматическим реконструкциям. Доклады Академии наук 2015. Т. 461(4), С. 447450 [Oshhepkova A.V., Kuz'min M.I., Bychinskij V.A., Solotchina Je.P., Chudnenko K.V. Solid solution models for the calculation of the mineral composition of lake Baikal bottom sediments: a new approach to paleoclimatic reconstructions. Doklady Earth Sciences 2015. Vol. 461(4), P. 447-450 (in Russ.)]

20. Смелый Р.В., Канева Е.В., Ощепкова А.В., Пашкова Г.В. Определение минерального состава кернов донных отложений оз. Зун-Торей методами рентгеновской дифракции и физикохимического моделирования с использованием данных рентгенофлуоресцентного анализа. Вопросы естествознания 2018. N. 1(15), C. 132-141 [Smelyy R.V., Kaneva E.V., Oshchepkova A.V., Pashkova G.V. Determination of the mineral composition of the bottom sediments core of lake zuntorei by x-ray diffraction method and physical-chemical modeling using x-ray fluorescent analysis data. Voprosy estestvoznaniya 2018. No. 1(15), P. 132-141 (in Russ.)]

21. DIFFRAC Plus Evaluation package EVA. User's Manual, Bruker AXS, Karlsruhe, Germany, 2007

22. Topas V4: General profile and structure analysis software for powder diffraction data. User's Manual, Bruker AXS, Karlsruhe, Germany, 2008.

23. ICDDProducts. [Электронный pecypc]: http://www.icdd.com/products/ (дата обращения 15.02.2019).

24. Hubbard C.R., Evans E.H., Smith D.K.. The Reference Intensity Ratio for Computer Simulated Powder Patterns. J. Appl. Cryst 1976. Vol. 169(9), P. 169-174.

25. Якимов И.С., Дубинин П.С., Залога А.Н., Пиксина О.Е., Якимов Я.И. Регуляризация методов бесстандартного рентгенофазового анализа. Журн. структурной химии 2011. Т. 52(2), C. 329-335 [Yakimov I.S., Dubinin P.S., Zaloga A.N., Piksina O.E., Yakimov Ya.I. Regularization of methods of a standardless x-ray phase analysis. Journal of Structural Chemistry 2011. Vol. 52(2), P. 319-325 (in Russ.)]

26. Чудненко К.В. Термодинамическое моделирование в геохимии: теория, алгоритмы, программное обеспечение, приложения. Новосибирск: Гео, 2010. 287 с. [Chudnenko K.V. Thermodynamic modeling in Geochemistry: theory, algorithms, software, applications. Novosibirsk, Geo Publ., 2010. 287 p. (in Russ.)] 